\title{
Sentidos do trabalho contemporâneo: as trajetórias identitárias como estratégia de investigação'
}

\author{
Maria Chalfin Coutinho ${ }^{2}$ \\ Universidade Federal de Santa Catarina
}

\begin{abstract}
O contexto produtivo contemporâneo vem passando por transformações significativas, afetando tanto as relações concretas, como as formas de ser dos sujeitos aí incluídos/excluídos. Tais transformações apontam para a necessidade de buscar estratégias de investigação capazes de apreender as complexas relações entre as dimensões subjetivas e objetivas do trabalho contemporâneo, sendo este o objetivo do presente artigo. Inicialmente, discute-se teoricamente os sentidos do trabalho e, depois, suas articulações com os processos identitários contemporâneos. Logo são apresentadas quatro investigações com diferentes coletivos de trabalhadores, a primeira com operários industriais, as outras com trabalhadores em situações precárias: ex-trabalhadores públicos, trabalhadores informais e cooperados. As pesquisas tiveram seu foco nas trajetórias ocupacionais e nos sentidos atribuídos ao trabalho pelos entrevistados e utilizaram como principal instrumento para coleta das informações a entrevista semi-estruturada. A investigação das trajetórias dos trabalhadores privilegiou sua dimensão temporal (passado, presente e futuro), considerando sua inserção laboral e os sentidos do trabalho. A análise dessas experiências de pesquisa permitiu tecer algumas considerações sobre as trajetórias identitárias enquanto estratégia de investigação capaz de ressignificar instrumentos tradicionais de pesquisa de modo a captar o caráter processual da condição humana e as configurações do trabalho contemporâneo (flexível, rápido, precário etc.).
\end{abstract}

Palavras-chave: Identidade, Trajetórias, Sentidos do trabalho, Método.

Senses of contemporary work: the trajectories of identification as a research strategy

The productive contemporary context is undergoing significant changes, affecting the concrete relations and the ways of being an included/excluded subject. The purpose of this article is to seek research strategies for understanding the complex relations between subjective and objective dimensions of contemporary work. Initially there is a discussion concerning the theories of the senses of work and then its correlations with contemporary identity processes. After that, four investigations, each one with a different group of workers, are presented: with industrial workers, former public workers, informal workers and cooperative members. The researches were focused on the occupational courses and the senses attributed to work by employees. The semi-structured interview was the main instrument for data collection. The investigation of the trajectories of workers aimed their past, present and future time dimension, considering their job's inclusion and their senses of work. The analysis of these experiences provided some considerations about the trajectories of identification as a research strategy that enable to redefine traditional research instruments. In this way, it was possible to figure out the procedural nature of the human condition and the characteristics of contemporary work (flexible, fast, precarious, etc.).

Keywords: Identity, Trajectories, Senses of work, Method.

\section{Introdução}

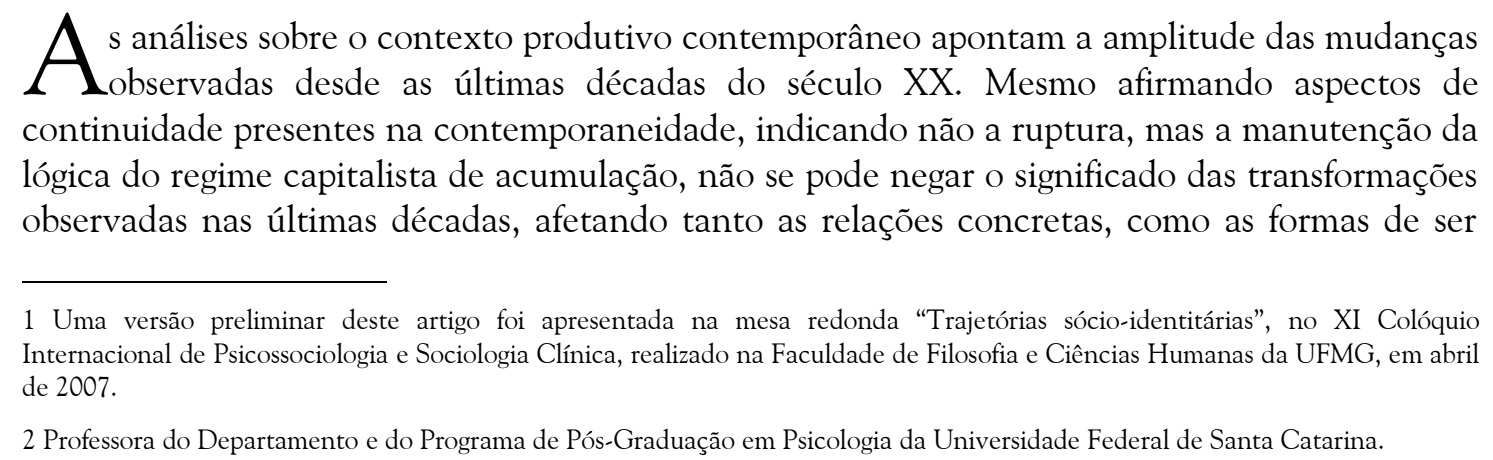


dos sujeitos incluídos/excluídos ${ }^{3}$ no atual contexto produtivo. Entre as estratégias de enfrentamento da chamada "crise estrutural do capitalismo", observou-se uma intensa reestruturação produtiva, através da qual buscou-se substituir os clássicos padrões produtivos, associados principalmente ao taylorismo-fordismo, por novos padrões de acumulação flexível (Antunes, 2000; Harvey, 2000).

A implementação dos processos produtivos flexíveis trouxe uma série de consequências para as relações de trabalho, entre as quais é possível destacar o crescimento do desemprego e de formas precárias ou flexíveis de emprego (Kovács, 2005; Pochmann, 2006; Singer, 2000). Assim sendo, a classe trabalhadora vai assumindo novas configurações, incorporando não só o proletariado fabril, mas a totalidade daqueles que vendem sua força de trabalho, incluindo "... o enorme leque de trabalhadores precarizados, terceirizados, fabris e de serviços, part time, que se caracteriza pelo vínculo de trabalho temporário, em expansão no mundo produtivo" (Antunes, 2003, pp. 218-219).

As mudanças associadas ao trabalho contemporâneo reiteram a importância do desenvolvimento de pesquisas sobre os sujeitos nesse contexto. Estudos no campo das diversas ciências humanas, em particular a psicologia, têm buscado diferentes estratégias teóricometodológicas para apreender as complexas relações entre as dimensões subjetivas e objetivas do trabalho contemporâneo.

Pretendo apresentar aqui uma proposta de estratégia qualitativa de pesquisa, focada em determinados coletivos de trabalhadores, visando identificar suas trajetórias ocupacionais e os sentidos que atribuem ao trabalho. Inicialmente farei uma breve síntese teórica sobre sentidos do trabalho, para, a seguir, tecer considerações sobre identidade e suas articulações com a categoria trabalho na contemporaneidade, considerados como processos em curso. Depois vou apresentar os procedimentos de pesquisa utilizados em quatro investigações realizadas, uma com trabalhadores de uma organização industrial e as outras três com coletivos em situações precárias de trabalho: ex-trabalhadores de uma empresa pública, trabalhadores informais e cooperados atuando na prestação de serviços. Por fim vou tecer algumas considerações sobre as trajetórias identitárias enquanto estratégia de investigação.

\section{Sentidos do trabalho contemporâneo}

Ao iniciar estas breves reflexões sobre o trabalho e seus sentidos na sociedade contemporânea, considero fundamental assinalar os pressupostos norteadores deste texto. Parto da concepção de trabalho como sendo toda a ação humana sobre a natureza com objetivo de transformá-la de acordo com uma necessidade (Marx, 1968). Configura-se, assim, uma relação dialética, de mútua transformação entre os seres humanos e a natureza.

O processo de trabalho tem como fim a produção de um valor de uso, ou seja, um produto criado para satisfazer necessidades humanas. Nas sociedades capitalistas, tal processo tem como objetivo a produção não só de valores de uso, mas, principalmente, de valores de troca, isto é mercadorias, com vistas à valorização do capital. Para Marx (1983), o trabalho no modo de produção capitalista deixa de hominizar e passa a alienar, pois o produto e o próprio processo de produção tornam-se estranhos ao trabalhador.

$\mathrm{Na}$ introdução deste artigo foram assinaladas as transformações pelas quais passa o mundo do trabalho contemporâneo. Esse quadro de mudanças abre espaço para o questionamento de diversas categorias teóricas, como a categoria trabalho. Mesmo 
considerando a pertinência do debate suscitado por diferentes autores, entre os quais é possível destacar Offe (1989) e Gorz (1982), sobre a perda da centralidade da categoria trabalho, assume-se aqui, o ponto de vista daqueles que, como Antunes (2000, 2003) e Harvey (2000), reafirmam o papel do trabalho como uma categoria fundante do ser humano e de suas formas de sociabilidade.

Pensar sobre o trabalho hoje é também assumir uma postura teórica sobre a sociedade atual. A opção pela categoria contemporaneidade ${ }^{4}$ supõe a compreensão das mudanças expressivas por que passam as sociedades capitalistas ocidentais, desde as últimas décadas do século XX, mas se opõe à ideia de ruptura com a sociedade moderna do século passado. Assim, pode-se pensar em transformações e continuidades, pois, como afirma Harvey (2000), “...há mais continuidade do que diferença..." (p. 111) nos movimentos históricos em curso.

Ao longo da história, as concepções de trabalho vêm passando por muitas transformações (Blanch, 2003; Borges \& Yamamoto, 2004). Blanch (2003) propõe uma definição abstrata e genérica de trabalho capaz de aglutinar todas as representações dos trabalhos concretos e específicos:

Quando falamos de trabalho, nos referimos a uma atividade humana, individual ou coletiva, de caráter social, complexa, dinâmica, mutante e irredutível a uma simples resposta instintiva ao imperativo biológico da sobrevivência material. Distingue-se de qualquer outro tipo de prática animal por sua natureza reflexiva, consciente, propositiva, estratégica, instrumental e moral (pp. 34-35, grifo no original, tradução da autora).

Em suas mudanças ao longo da história, o trabalho adota o caráter de sustento material e toma a forma de emprego - ou trabalho assalariado na sociedade capitalista industrial - a partir do século XVIII. Com as crises do mercado de trabalho capitalista surgem o desemprego e, mais recentemente, depois de meados do século XX, o subemprego ou emprego de baixa qualidade. As categorias emprego, desemprego e subemprego são consideradas por Blanch (2003) como tipos ideais, pois é possível observar inúmeras formas de relações de trabalho concretas. Tal amplitude de situações laborais está fortemente associada às novas configurações da classe trabalhadoras já assinaladas.

Ao realizar uma análise do mercado de trabalho no Brasil no final do século XX, Pochmann (2006) identifica a mais grave "crise de emprego" da história ${ }^{5}$, ocasionando uma desestruturação em suas formas caracterizada por três componentes:

O primeiro está associado à presença, em larga escala, do desemprego em praticamente todos os segmentos sociais. $\mathrm{O}$ segundo componente (...) diz respeito à regressão dos postos de trabalho formais, o que contribui para a perda da participação do emprego assalariado no total das ocupações, também conhecido como desassalariamento (...) Por fim, o terceiro componente refere-se ao processo de destruição dos postos de trabalho de melhor qualidade, sem a mesma contrapartida nos empregos criados (p. 60).

Kovács (2005), como resultado de pesquisas realizadas em Portugal, identificou diferentes formas de emprego flexível presentes na sociedade capitalista contemporânea: trabalho temporário, autoemprego, trabalho com tempo parcial, trabalho a domicílio etc. Tais formas emergem em decorrência da crise do modelo de emprego predominante nos países de capitalismo avançado.

Esta crise se manifesta no aumento do desemprego e na redução do emprego seguro e regular, efectuado em tempo integral numa determinada empresa com base num vínculo

4 Para aprofundar o debate sobre contemporaneidade e trabalho ver Coutinho, Krawulski e Soares (2007).

$5 \mathrm{O}$ autor usou como fonte de referência dados oriundos da Pesquisa Nacional por Amostras de Domicílio (PNAD) do Instituto Brasileiro de Geografia e Estatística (IBGE), focando principalmente a evolução do desemprego no período de 1992 a 2002. 
contratual estável e num compromisso a longo prazo entre empregador e empregado, a favor da difusão de uma grande variedade de formas de emprego, cujo denominador comum é a flexibilidade em termos contratuais, de tempo de trabalho, de espaço e de estatutos (Kovács, 2005, p. 12).

Ao analisar as formas emprego contemporâneas, Kovács (2005) opta pela expressão "empregos flexíveis", pois a considera mais adequada quando comparada a outras denominações utilizadas, como "trabalho atípico" ou "novas formas de trabalho/emprego". Estas denominações aparecem como contraposição às formas contratuais reguladas típicas do emprego fordista, que teriam configurado-se como hegemônicas em países capitalistas avançados. Considero o uso do conceito de "emprego flexível" particularmente pertinente em pesquisas realizadas em países periféricos, como o Brasil, nos quais as formas reguladas de emprego sempre conviveram com outras formas não reguladas ou informais.

As mudanças nas formas de trabalho e emprego trazem implicações objetivas e subjetivas, já que a noção de trabalho, tal como coloca Blanch (2003), envolve tanto as condições socioeconômicas nas quais essa atividade humana desenvolve-se, como o significado, o sentido e o valor socioculturais dessa experiência. As condições de trabalho são relativas às circunstâncias nas quais ele ocorre, já os significados remetem aos diferentes valores e concepções sobre trabalho.

Ao longo da história, o trabalho pode assumir tanto conotações negativas, como positivas (Bastos, Pinho \& Costa, 1995). Nesse sentido, Blanch (2003) identifica três posições: polo negativo, centro do contínuo e polo positivo. O polo negativo é a "... representação de trabalho como maldição, castigo, jugo, estigma, coerção, esforço e penalidade” (p. 45). No centro do contínuo estariam as representações de trabalho "... como uma mera função instrumental a serviço da sobrevivência material, a qual cabe dedicar toda e só a atenção necessária para o alcance deste objetivo..." (p. 46). No polo positivo, o trabalho é visto como "missão, vocação, caminho, valor, fonte de satisfação e de auto-realização" (p. 47). Na sociedade industrial, o sentido positivo de trabalho domina a ideologia que rege a vida cotidiana. Trata-se da ética do trabalho, analisada por Weber em sua clássica obra A ética protestante e o espírito do capitalismo (Blanch, 2003; Borges \& Yamamoto, 2004).

Considerando as transformações pelas quais passam as relações de trabalho contemporâneas, vários autores vêm investigando quais as implicações dessas mudanças para os sentidos e os significados atribuídos ao trabalho. Ao analisar a literatura sobre o tema, Tolfo, Coutinho, Almeida, Baasch e Cugnier (2005) identificaram diferentes vertentes teóricas e as organizaram em quatro abordagens: sócio-histórica, construcionista, cognitivista e humanista.

Muitos estudos empíricos sobre sentidos e significados do trabalho que vêm sendo realizados no Brasil, em especial aqueles inseridos nas abordagens cognitivista e humanista, têm ancorado-se nas investigações desenvolvidas pelo Meaning of Work (MOW) (Tolfo et al., 2005). MOW é um grupo de pesquisas internacional, sediado no Canadá, que investiga o sentido e a centralidade do trabalho em diversos países, desde a década de 1970. Esses pesquisadores estabeleceram, a partir de estudos empíricos, as seguintes dimensões: centralidade do trabalho (importância atribuída a ele na vida da pessoa em um determinado momento), normas sociais sobre o trabalho (derivadas de valores morais relacionados ao trabalho) e resultados valorizados do trabalho, dimensão relacionada a motivações que levam a trabalhar (Blanch, 2003; Tolfo \& Piccinini, 2007).

Além da diversidade de pontos de vista teóricos, os estudos empíricos nesse campo optam por usar ora a expressão sentidos, ora significados do trabalho, às vezes como sinônimos, às vezes como conceitos diferentes (Tolfo et al., 2005). Neste texto adotou-se uma perspectiva que articula as abordagens sócio-histórica e construcionista, tomando da primeira a ênfase na relação dialética entre objetivo e subjetivo e, da segunda, o lugar de destaque ocupado pela análise do cotidiano. Apesar das diferenças, as duas abordagens compartilham a compreensão 
sobre a indissociabilidade entre sujeito e realidade, sendo os sentidos ou significados produzidos pelos sujeitos a partir de suas experiências concretas. Para tanto, serão tomadas como ponto de partida as seguintes concepções:

... os significados como construções elaboradas coletivamente em um determinado contexto histórico, econômico e social concreto. Já os sentidos são uma produção pessoal decorrente da apreensão individual dos significados coletivos, nas experiências cotidianas. É importante ressaltar as transformações porque passam os sentidos e os significados, uma vez que são construídos em uma relação dialética com a realidade (Tolfo et al., 2005).

Considerando a relação dialética entre sentidos e significados, a análise dos sentidos produzidos pelos sujeitos deve sempre considerar suas relações com os significados produzidos coletivamente e vice-versa. Do mesmo modo, também é importante considerar a articulação entre os processos identitários e de construção de sentidos pelos sujeitos em seu cotidiano de trabalho. A seguir vou apresentar uma breve discussão teórica sobre processos identitários e suas relações com o trabalho contemporâneo, como forma de subsidiar teoricamente as investigações analisadas neste artigo.

\section{Processos identitários e trabalho na contemporaneidade}

O estudo de questões relativas à dimensão subjetiva dos trabalhadores constitui-se em um importante campo de investigação para as diversas disciplinas que analisam o homem em suas relações de trabalho. Entre as categorias teóricas para o estudo da dimensão subjetiva nesse campo está a identidade.

A categoria identidade tem sido objeto de análise de diferentes estudiosos das ciências humanas, mas, desde as últimas décadas do século XX, sua capacidade explicativa para os fenômenos humanos vem sendo fortemente questionada. Tal debate emerge no quadro das diversas crises que abalaram os países capitalistas ocidentais.

Sem aprofundar a discussão sobre as crises, pois não caberia na proposta do presente texto, considero importante afirmar que a sociedade contemporânea vem assumindo configurações que certamente colocam em xeque os modelos explicativos tradicionais das ciências humanas. Entretanto, tal como assinalei antes, a contemporaneidade é eivada de contradições e, sendo assim, pode ser compreendida como marcada por mudanças, mas também, e ao mesmo tempo, por continuidades.

As reflexões teóricas sobre os processos identitários frequentemente tomam como referência os conceitos de identidades pessoais e coletivas. $O$ primeiro corresponderia ao "... sentido de si mesmo que se constrói, reflexiva e narrativamente, e que orienta para as ações significativas de cada indivíduo...” (Stecher, Godoy \& Díaz, 2005, p. 89). Já o segundo é compreendido de modo indissociável ao primeiro, pois "... as identidades pessoais supõem sempre as identidades coletivas, isto é, os indivíduos sempre definem o que são como decorrência do reconhecimento de seu pertencimento a certos coletivos ou categorias sociais com as quais se identifica..." (p. 89, grifos no original, tradução da autora).

A compreensão de ambos processos como inseparáveis já estava presente na afirmação de Martin-Baró (1988): "Não há identidade pessoal que não seja ao mesmo tempo e da mesma forma identidade social" (p. 117, tradução da autora). Do mesmo modo, Dubar (2006) questiona a separação entre as identidades pessoal e social. Ao analisar as "grandes teorias" sobre socialização, no campo das ciências sociais, o autor distingue duas grandes orientações teóricas opostas: um ponto de vista considerado como "psicologizante" ou "essencialista" - 
atribuindo ao eu ou self uma realidade substantiva e autônoma -, enquanto o ponto de vista "sociologista" ou "relativista" considera o eu ou self uma ilusão, totalmente dependente da sociedade na qual se insere.

O autor propõe superar a polarização acima e adota uma perspectiva relacional, expressa através da articulação entre investigações sobre as "trajetórias objetivas" - relativas às posições sociais objetivamente ocupadas pelos sujeitos - e sobre as "trajetórias subjetivas" ou "formas identitárias" - relativas à biografia dos entrevistados.

O conceito de formas identitárias foi proposto por Dubar (2006) para apreender, em situação de entrevista de pesquisa, o discurso de entrevistados sobre suas práticas, trajetórias, crenças e projetos relativos a suas experiências laborais e de formação. Esse conceito foi posteriormente redefinido, passando a ser nomeado como formas narrativas, que consideradas como "... ao mesmo tempo modos de categorização e tipos de argumentação, que permitem a sujeitos (...) falar de si, tentando convencer seu interlocutor do sentido de seu percurso não somente profissional mas também pessoal" (Demazière \& Dubar, 2006, p. 179).

Diante da necessidade de repensar conceitos-chave, como identidade e trabalho, é possível afirmar, tal como faz Hall (2004) em relação ao primeiro, de que se trata de conceitos "sob-rasura", mas, dado não terem sido superados, precisamos continuar pensado com eles, não mais dentro dos mesmos paradigmas, mas de "formas destotalizadas e desconstruídas". Novas concepções teóricas vêm emergindo para apreender as implicações das "crises das identidades" para os sujeitos.

A globalização das trocas econômicas, a flexibilização dos mercados de emprego e a reticularização das formas de organização provocaram uma reconfiguração das formas identitárias no campo profissional: as identidades "de rede" são potencialmente as mais valorizadas. Supõem mobilidades voluntárias "externas" e formas de acumulação de competências "distintivas" que desenham percursos profissionais de um novo tipo (Demazière \& Dubar, 2006, p. 186).

Considerando a "crise das identidades" e a necessidade de repensar o conceito, um caminho possível é fazer sua articulação com o processo de identificação, oriundo da psicanálise tal como foi feito por Hall (2004) e, mais recentemente, por Coutinho, Krawulski e Soares (2007).

A articulação entre os conceitos de identificação e identidade reitera a processualidade dos processos identitários. Tomando referência na concepção freudiana de identificação e compreendendo tratar-se de um processo psicológico através do qual o sujeito apreende características do outro, de modo a transformar-se (total ou parcialmente), a partir desse modelo (Laplanche \& Pontalis, 1971), identidade pode ser compreendida como:

... um momento deste processo, sempre instável e transitório, um "retrato", aquilo que emerge e se mantém do processo de identificação, e se expressa nas interações, não obstante as mudanças em curso. Portanto, os dois conceitos não podem ser compreendidos separadamente (Coutinho, Krawulski \& Soares, 2007, p. 35).

Ao analisar as noções de identidade, sujeito e indivíduo propostas por alguns sociólogos, Gaulejac (2005) também chama a atenção para os processos de identificação, apontando para a existência de “... uma dialética permanente entre a identidade herdada [genealógica e familiar] e a identidade adquirida, entre a diacronia e a sincronia ${ }^{6}$, entre a identidade objetiva (estatutária) a identidade esperada" (p. 62).

6 "O indivíduo se constrói como um sujeito na sua confrontação com suas contradições entre a diacronia (interiorização de maneiras de ser, de pensar e de agir ligadas à sua história) e a sincronia (adaptação de suas condutas a um dado contexto)" (Gaulejac, 2005, p. 69). 
No atual contexto, marcado por fragmentações, descontinuidades e efemeridades, certamente a constituição das identidades torna-se um processo bem mais complexo do que nas sociedades modernas, favorecendo a fragmentação dos sujeitos (Coutinho, Krawulski \& Soares, 2007). Nesse sentido, as identidades devem ser compreendidas como identificações em curso, como faz Santos (2001). O sujeito busca reconfigurar os processos identitários, advindos de suas experiências laborais, de modo a articular alguma continuidade na mudança, pois

... continua procurando organizar suas experiências cotidianas em um conjunto relativamente estável, que pode ser percebido como o seu eu. É a continuidade da busca pela construção de uma biografia que tenha e faça sentido, para o próprio sujeito e para o mundo em seu entorno (Coutinho, Krawulski \& Soares, 2007, p. 19).

A partir de uma série de estudos sobre sujeitos com diferentes formas de inserção no atual contexto produtivo, considero a investigação das trajetórias ocupacionais como uma estratégia promissora para compreensão das continuidades e das mudanças nos modos de ser trabalhador na contemporaneidade. A pluralidade desses modos de ser justifica "... o interesse teórico e metodológico pelas trajetórias ocupacionais de trabalhadores" (Guimarães \& Hirata, 2006, p. 12).

Tomando como referência as reflexões teóricas apresentadas até aqui sobre as categorias teóricas - sentidos do trabalho e processos identitários -, apresento a seguir algumas experiências de pesquisas, desenvolvidas ou orientadas por mim, ancoradas nessas articulações teóricas.

\section{Investigando trajetórias identitárias no âmbito do trabalho}

Serão apresentadas resumidamente aqui quatro investigações realizadas com diferentes coletivos de trabalhadores, a primeira com operários de uma organização industrial, enquanto as outras referem-se a trabalhadores inseridos em situações precárias de trabalho: extrabalhadores de uma empresa pública, trabalhadores informais e cooperados.

As pesquisas tiveram seu foco nas trajetórias ocupacionais e nos sentidos atribuídos ao trabalho e utilizaram abordagens qualitativas de investigação. Para Bogdan e Biklen (1994), esse tipo de investigação permite melhor compreensão e aprofundamento das formas pela quais os sentidos são produzidos pelos sujeitos. Biasoli-Alves (1998) destaca o quanto tal modalidade guarda fidelidade ao universo cotidiano dos sujeitos. Enquanto Rey (2002) considera esse tipo de abordagem como uma via para apreender as singularidades dos sujeitos - irregularidades, dinâmicas, interações etc. - em relação com a totalidade.

Cada pesquisa consistiu em um estudo de caso com determinado coletivo de trabalhadores, compreendendo tratar-se de "... uma categoria de pesquisa cujo objeto é uma unidade que se analisa profundamente" (Triviños, 1987, p. 133). De acordo com Heloani e Capitão (2007), essa modalidade de investigação é bastante aceita e utilizada nas ciências humanas, pois

O estudo de caso pode ser um meio de fazer ciência, principalmente quando a natureza do fenômeno observado é multi-determinada e interessa conhecer de modo profundo e abrangente a singularidade de uma dada situação, mesmo que, em última instância, busque-se um conhecimento que, de alguma forma ou em alguns aspectos, possa ser generalizável (p. 31). 
O principal procedimento para coleta das informações utilizado nos quatro estudos foi a entrevista semi-estruturada. Em dois deles, as pesquisas na organização industrial e na cooperativa, também foram realizadas observações do cotidiano de trabalho, com registro em diário de campo.

Em todos os estudos foi utilizada a análise qualitativa de conteúdo das informações coletadas, como forma de apreender os sentidos do texto (Franco, 1994). Segundo Rey (2002), essa análise "... é aberta, processual e construtiva e não pretende reduzir o conteúdo a categorias restritivas” (p. 146).

Através do processo de análise de conteúdo, as falas dos trabalhadores foram organizadas em categorias temáticas. Segundo Franco (1996), "formular categorias (...) é (...) um processo longo, difícil e desafiante" (p. 174), no qual podem ser utilizadas categorias elaboradas a priori ou a posteriori. No primeiro caso, busca-se classificar o material sob análise (transcrição das entrevistas ou registros do diário de campo) em categorias pré-definidas a partir da teoria. Já na classificação a posteriori, as categorias “... emergem da 'fala', do discurso, do conteúdo das respostas". Nos estudos apresentados aqui houve uma combinação das duas formas de categorização.

\section{Trabalhadores de uma organização participativa}

Trata-se de uma investigação sobre as trajetórias de operários de um grupo empresarial com estratégias participativas de gestão. Essa pesquisa revelou o quanto trabalhadores, mesmo com uma inserção formal e regulada no trabalho, são afetados pela precariedade do contexto produtivo contemporâneo.

O objetivo desse estudo foi investigar as possibilidades de participação e os perfis profissionais de trabalhadores inseridos em três unidades de um grupo industrial catarinense que desenvolvia estratégias participativas de gestão dos seus recursos humanos (Coutinho, 2006).

A coleta de informações foi realizada separadamente em três unidades industriais do grupo empresarial investigado através de observações e entrevistas com um total de 43 trabalhadores. Já nessa pesquisa considerei importante investigar a trajetória laboral dos trabalhadores em sua dimensão temporal: passado (formação, experiência anterior e trajetória na empresa), presente (exercício profissional atual na empresa e fora dela) e futuro (expectativas relacionadas ao trabalho). Foram identificadas concepções e sentidos produzidos pelos trabalhadores a partir de suas experiências no mundo do trabalho, em especial, foi alvo dessa investigação a questão da participação no trabalho, compreendendo as práticas possíveis e as concepções decorrentes.

Os resultados encontrados apontaram para a emergência de dois tipos de trabalhadores: antigos e novos. Os primeiros com menor escolaridade e maior saber-fazer adquirido na prática, mas sob o risco de exclusão. Já os jovens apresentavam maior nível de instrução formal, habilidade para o desenvolvimento de tarefas variadas e expectativas de progresso profissional rápido.

A análise das possibilidades de participação, dentro e fora da situação laboral, revelou a presença apenas de práticas limitadas ou parciais. Mesmo estimulando o "sentimento de participar", essas práticas não ampliavam o grau de influência dos trabalhadores, constituindose em formas de "pseudoparticipação" (Pateman, 1992). Como decorrência dessas experiências concretas, os trabalhadores tendem a expressar sentidos também bastante limitados para participação, geralmente relacionados a suas atividades cotidianas na empresa ou na vida familiar, sendo poucos os que compreendem o participar como uma inserção em esferas mais amplas das relações sociais. 


\section{Ex-trabalhadores de uma empresa pública}

Este estudo foi realizado com o objetivo de investigar as vivências de trabalhadores egressos de programas de reestruturação de pessoal realizados em uma empresa estatal federal de energia elétrica, com sede localizada na região da Grande Florianópolis (Coutinho \& Guerra, 2006). A estatal passou por um intenso processo de enxugamento durante os anos 1990, que culminou com a cisão em 1997, dividindo-se em duas empresas, uma responsável pelas atividades de transmissão, mantida como estatal federal, e outra empresa geradora de energia, privatizada em 1998.

Na última década do século XX, no Brasil, foi possível observar a intensificação de processos de reestruturação produtiva de diversos tipos, entre os quais destacam-se aqui os programas de demissão incentivada implementados em empresas estatais de setores estratégicos de serviços, tais como as telecomunicações, a energia elétrica e os bancos estatais. Dessa forma, foram sendo preparadas para a privatização importantes empresas estatais, visando atender às reformas impostas por políticas neoliberais de organismos financeiros internacionais (Jesus, 1998).

Nesse estudo foram entrevistados dez ex-trabalhadores, cinco homens e cinco mulheres, desligados da estatal ao longo dos anos 1990. A análise do conteúdo das entrevistas permitiu a organização dos dados nas seguintes categorias temáticas: trajetória profissional na empresa, mudanças, desligamentos e trajetória profissional após os desligamentos.

Os resultados evidenciaram o forte vínculo dos entrevistados com a empresa, pois todos trabalharam ali por longos períodos, o que, certamente, contribuiu para dificultar o desligamento e a reconstrução de suas trajetórias profissionais. Do seu ponto de vista, as mudanças foram implementadas pela administração de cima para baixo, atendendo a interesses políticos, sendo os trabalhadores pressionados a aderir aos programas de demissão incentivada. Desse modo, apesar de alguns terem assinalado sua compreensão sobre a necessidade de reestruturar a empresa, para todos essa reestruturação significou consequências negativas para a sociedade e para eles próprios.

As trajetórias profissionais dos egressos entrevistados foram fortemente marcadas pela vida profissional na empresa. Os programas de enxugamento e os desligamentos tiveram profundas implicações sobre a vida e a saúde de cada um deles e de suas famílias. Depois do desligamento, os entrevistados, particularmente as mulheres ${ }^{7}$, relatam as dificuldades de reinserção no mercado de trabalho. Um dos fatores destacados como restritivos à inserção foi a idade, pois todos tinham mais de quarenta anos quando foram desligados e, portanto, seriam considerados "velhos" para o mercado (Antunes, 2000). Foi um processo difícil, para o qual uns estavam mais preparados, outros menos, requerendo capacidade de adaptação às novas realidades do mundo do trabalho.

\section{Trabalhadores informais}

Trata-se de uma dissertação de mestrado, cujo principal objetivo foi investigar o processo de construção das identidades de trabalhadores informais que atuam em Florianópolis, SC (Campos, 2005). Para tanto, foram entrevistados sete trabalhadores em situação de informalidade, sendo dois trabalhadores domésticos (faxineiro e diarista), um pedreiro, duas guias de turismo e duas professoras de inglês.

O sentido de informalidade utilizado foi o proposto por Alves (2003), que inclui os trabalhadores em atividades informais tradicionais e os trabalhadores inseridos em novas e precárias relações de trabalho, sem um contrato de trabalho formalizado. Apenas uma

7 No momento da entrevista apenas um participante, entre os homens, tinha emprego formal, três exerciam atividades com vínculos informais e um estava desempregado. Já entre as mulheres, nenhuma exercia atividades remuneradas. 
entrevistada era assalariada, mas sem registro formal. Os restantes eram trabalhadores informais tradicionais que trabalhavam por conta-própria.

As entrevistas realizadas tiveram como referência um roteiro semi-estruturado, no qual eram solicitados, inicialmente, os dados de identificação dos participantes, depois eles eram questionados em torno dos seguintes campos temáticos: atividade atual, histórico profissional, vida pessoal e projetos profissionais, sentidos do trabalho e do emprego e identidade (compreensão acerca de si).

A análise do conteúdo das entrevistas possibilitou a emergência das seguintes categorias e sub-categorias temáticas: a) trajetórias profissionais e informalidades (trajetória pregressa, informalidades e projetos profissionais para o futuro) e b) identidades (identidades e trabalho e identidades e informalidades).

No que diz respeito às trajetórias pregressas, foi possível identificar dois grupos: um composto pelos participantes com menor escolaridade e inserção precoce no mercado de trabalho e outro formado por aqueles com maior nível de escolarização e ingresso mais tardio nas atividades produtivas. Para os primeiros, a inclusão em determinada ocupação deu-se como sequência de suas vidas ou das profissões dos pais. Já os segundos assumem uma profissão como resultado de uma formação, mesmo quando se trata de uma ocupação não planejada ou provisória.

Os resultados da pesquisa revelaram ser a informalidade uma opção e não a falta de opção dos participantes, pois todos tinham tido experiências de inserção no mercado formal, consideradas como ruins e, portanto, não pretendiam retornam àquela condição. Eles veem na situação informal possibilidades de maiores ganhos e de melhores condições de trabalho, mas trazem a dificuldade de custear os encargos trabalhistas e a incerteza de manutenção da renda como características negativas do trabalho informal.

As peculiaridades do trabalho informal são tidas como aspectos que diferenciam os entrevistados dos trabalhadores do mercado formal e com as quais se identificam e reconhecem-se. A formalização é associada a uma realidade precária, com longas jornadas e baixa remuneração, sendo a informalidade uma alternativa, ao oferecer melhores rendimentos e mais liberdade. Entretanto, os entrevistados mesmo optando pela informalidade, sentem-se inseguros quanto ao futuro pela ausência de direitos trabalhistas e previdenciários.

\section{Trabalhadores de uma cooperativa de prestação de serviços}

Também esta pesquisa é uma dissertação de mestrado, cujo objetivo principal foi investigar os sentidos do trabalho para sujeitos inseridos em um "empreendimento solidário" (Dal Magro, 2006). Tratava-se de uma cooperativa de serviços gerais situada em um município da região oeste do estado de Santa Catarina, cuja principal atividade, a varrição das ruas, era realizada em convênio com a prefeitura da cidade.

Assim como na primeira pesquisa apresentada, nesse estudo a observação foi também um instrumento utilizado para a coleta de informações. $O$ uso desse instrumento foi possível pelo fato dos participantes estarem inseridos em uma mesma organização, ainda que caracterizada por vínculos não formais de trabalho. Foram entrevistados nove trabalhadores, todos integrantes da cooperativa havia pelo menos seis meses, com baixa escolaridade (nenhum havia completado o ensino fundamental) e idades entre 38 e 58 anos. As entrevistas seguiram um roteiro, cujas perguntas cobriam os seguintes temas: trajetórias de trabalho, sentidos do trabalho e sentidos do cooperativismo.

As categorias temáticas que emergiram da análise dos conteúdos foram as seguintes: a) sentidos do trabalho (trabalho enquanto forma de subsistência e enquanto forma de reconhecimento ou desvalorização social); b) sentidos do cooperativismo (a autogestão no 
espaço da cooperativa, atravessamentos políticos partidários, processos de capacitação e suas implicações na apropriação dos princípios da economia solidária e sobre a solidariedade).

A análise das categorias acima revelou uma compreensão de trabalho como forma de subsistência, remetendo às concepções características do contexto capitalista, mas também apontou os sentidos de reconhecimento ou desvalorização social. A inserção da maior parte dos entrevistados no empreendimento foi motivada por necessidades econômicas, dificultando sua compreensão sobre o significado de participar de uma cooperativa e sobre as diferenças entre ser cooperado e ser empregado. Entretanto, o ingresso na cooperativa foi também compreendido como valorização e reconhecimento, tendo em vista a maior parte dos entrevistados relatarem histórias de desemprego e dificuldades econômicas anteriores, tendo apontado o sofrimento psicológico associado a essas condições (Sawaia, 1999b).

Evidenciou-se uma articulação entre os sentidos atribuídos pelos participantes ao trabalho e ao cooperativismo. Apesar das dificuldades do empreendimento e dos atravessamentos políticos partidários ocorridos nesse espaço ${ }^{8}$, os entrevistados foram capazes de expressar forte solidariedade em relação, não só aos colegas, mas a outros trabalhadores. A experiência na cooperativa abriu espaço para a compreensão de outras formas possíveis de relações de trabalho, não apenas aquelas pautadas pela compra e venda da força de trabalho.

\section{Trajetórias identitárias como estratégia de investigação}

Pensar nas estratégias de investigação utilizadas significa voltar o olhar para os caminhos percorridos nos percursos de pesquisa e, portanto, propor uma reflexão sobre método. "O vocábulo método vem do grego e quer dizer caminho para se chegar - para além de um obstáculo - a um fim" (Heloani \& Capitão, 2007, p. 25). Esse caminho está certamente articulado com as concepções teóricas de cada pesquisa. Não é, entretanto, um percurso único, já determinado a priori, mas algo construído em cada experiência, no diálogo entre pesquisadores e sujeitos participantes das investigações.

Mesmo enfatizando a necessidade de não estabelecer uma estrutura rígida de investigação, considero importante apresentar aqui as contribuições das trajetórias identitárias enquanto estratégia de investigação capaz de apreender as complexas relações entre os sujeitos e o trabalho contemporâneo. Cabe destacar que tal estratégia assenta-se na concepção dialética da relação homem-sociedade. Nesse sentido, considero que as abordagens qualitativas de investigação têm maior possibilidade de apreender os sujeitos em suas singularidades e nas relações com o coletivo.

A proposta das trajetórias identitárias ${ }^{9}$ buscou inspiração nos métodos desenvolvidos por Dubar (2006) e Gaulejac (2000). O primeiro investiga as "trajetórias sociais e formas identitárias" de sujeitos no decorrer de sua existência, considerando as dimensões objetivas e subjetivas como indissociáveis e, portanto, adotando um ponto de vista relacional sobre a constituição das identidades. Já Gaulejac (2000) propõe a investigação das "trajetórias sociais", buscando compreender as articulações entre os aspectos sociológicos e psicológicos das histórias singulares.

Foram apresentadas quatro investigações, configuradas na forma de estudos de caso, cujo principal instrumento de coleta de dados foi a entrevista semi-estruturada. Nas

8 Esses fatores levaram à transformação da cooperativa em uma empresa, pouco tempo após a pesquisa ter sido finalizada.

9 Tal proposta vem sendo desenvolvida, juntamente com as colegas que atuam comigo no âmbito da linha de pesquisa "Trajetórias no trabalho e processos identitários", da área de "Práticas sociais e constituição do sujeito" do Programa de Pós-Graduação em Psicologia (PPGP) da UFSC. 
entrevistas, buscou-se investigar as trajetórias ocupacionais dos sujeitos ao longo de sua vida laboral, para, assim, compreender os sentidos produzidos por eles sobre o mundo do trabalho. Cada estudo tinha como foco alguns aspectos do trabalho contemporâneo (participação, programas de reestruturação, informalidades e empreendimentos solidários), visualizados através das experiências singulares dos entrevistados.

A investigação das trajetórias identitárias dá destaque à dimensão temporal (passado, presente e futuro) da vida laboral dos sujeitos entrevistados. $O$ passado remete à inserção no mundo do trabalho, incluindo desde as possibilidades ou não de escolarização e de formação profissional, até as diferentes experiências profissionais anteriores.

A análise das trajetórias anteriores dos entrevistados nos quatro estudos de caso mostra peculiaridades de cada coletivo, bem como similitudes e diferenças de cada sujeito. Assim, os resultados dessas pesquisas reiteram a relação indissociável entre as identidades pessoais e coletivas.

Entre os trabalhadores da organização participativa, foi possível observar que os antigos, com menor escolaridade, correm o risco de serem excluídos. De alguma maneira ser antigo, mais velho ou ter menor escolaridade constituem-se como fatores restritivos à inserção no mercado de trabalho. Esses fatores repetem-se nos sujeitos dos outros estudos de caso, como todos os egressos de programas de reestruturação, os informais menos escolarizados e todos os cooperados.

Analisar diferentes coletivos de trabalhadores permitiu a apreensão da dialética da exclusão/inclusão, constituída pelas tramas vivenciadas cotidianamente no mundo do trabalho. Nesse sentido, as formas de inserção no mercado de trabalho são atravessadas por inúmeros fatores. Assim, diante da precarização e da exclusão do mercado formal, estar na situação de informalidade pode ser uma opção, do mesmo modo como fazer parte de uma cooperativa pode corresponder mais à necessidade de ter um emprego do que à opção pelo cooperativismo.

A análise das trajetórias laborais dos sujeitos investigados nos quatro estudos revela histórias construídas sempre em diálogo com os contextos de trabalho vivenciados por eles. Pensar dessa forma não significa assumir uma concepção determinista, na qual os traços identitários e os sentidos produzidos no passado não possam ser ressignificados no presente.

O presente diz respeito às vivências atuais no contexto produtivo contemporâneo. No caso dos estudos apresentados, tal contexto pode ser significado através de negatividades, mas, também, de positividades. Os aspectos negativos referem-se à situação de precariedade, como o risco de exclusão dos antigos, as dificuldades de reinserção dos egressos, a insegurança do trabalho informal e os atravessamentos e as contradições presentes na cooperativa. Já as positividades podem ser associadas a: possibilidades, mesmo limitadas, de participação; reinserção no mercado de trabalho, mesmo com vínculos informais, de alguns egressos; a opção pela informalidade dos trabalhadores informais e a solidariedade dos cooperados.

A história laboral e as vivências ocupacionais atuais dos entrevistados vão pautar seus projetos. Nesse sentido, o olhar para o futuro é marcado pelas contradições do passado e do presente e pelas possibilidades de cada um ressignificar os sentidos produzidos ao longo de suas trajetórias identitárias. As falas dos trabalhadores entrevistados revelam o lugar chave ocupado pelo trabalho ao longo de suas vidas, reiterando, assim, a centralidade do trabalho na sociedade contemporânea.

O objetivo deste texto foi apresentar as trajetórias identitárias como uma estratégia especialmente fecunda para investigar sujeitos inseridos na sociedade do trabalho contemporânea. Essa forma de pesquisa possibilitou apreender a processualidade das constituições identitárias dos trabalhadores entrevistados, bem como as contradições presentes nos sentidos produzidos por eles, a partir de suas trajetórias ocupacionais.

\section{0}




\section{Referências}

Alves, M. A. (2003). Formas contemporâneas do trabalho informal no Brasil. In Anais do VIII Encontro Nacional de Estudos do Trabalho, São Paulo: Associação Brasileira de Estudos do Trabalho.

Antunes, R. (2000). Os sentidos do trabalho: ensaio sobre a afirmação e a negação do trabalho. São Paulo: Boitempo.

Antunes, R. (2003). A nova morfologia do trabalho e o desenho multifacetado da ação coletiva. In M. A. Santana \& J. R. Ramalho (Orgs.), Além da fábrica: trabalhadores, sindicatos e a nova questão social (pp. 213-224). São Paulo: Boitempo.

Bastos, A. V. B., Pinho, A. P. \& Costa, C. A. (1995). Significado do trabalho: um estudo entre trabalhadores de organizações formais. Revista de Administração de Empresas, 35 (6), 20-29.

Biasoli-Alves, Z. M. M. (1998). A pesquisa em psicologia: análise de métodos e estratégias na construção de um conhecimento que se pretende científico. In G. Romanelli \& Z. M. M. Biasoli-Alves (Orgs.), Diálogos metodológicos sobre prática de pesquisa (pp. 135-157). Ribeirão Preto: Legis Summa.

Blanch, J. M. (2003). Trabajar en la modernidad industrial. In J. M. Blanch (Org.), Teoría de las relaciones laborales: fundamentos (pp. 19-148). Barcelona: UOC.

Bogdan, R. \& Biklen, S. K. (1994). Investigação qualitativa em educação: uma introdução à teoria e aos métodos. Porto, Portugal: Porto Editora.

Borges, L. B. \& Yamamoto, O. H. (2004). O mundo do trabalho. In J. C. Zanelli, J. E. Borges-Andrade \& A. V. Bastos (Orgs.), Psicologia, organizações e trabalho no Brasil (pp. 25-61). Porto Alegre: Artmed.

Campos, M. (2005). Identidades e informalidades: um estudo com trabalhadores do setor informal de Florianópolis-SC. Dissertação de Mestrado, Programa de Pós-Graduação em Psicologia, Universidade Federal de Santa Catarina, Florianópolis.

Coutinho, M. C. (2006). Participação no trabalho. São Paulo: Casa do Psicólogo/All Books.

Coutinho, M. C. \& Guerra, L. J. (2006). Implicações de programas de enxugamento para trabalhadores egressos de uma empresa estatal de energia elétrica. In V. Piccinini, L. Holzmann \& I. Kóvacs (Orgs.), Mosaico do trabalho na sociedade contemporânea: persistências e inovações (pp. 203-225). Porto Alegre: UFRGS.

Coutinho, M. C., Krawulski, E. \& Soares, D. H. P. (2007). Identidade e trabalho na contemporaneidade: repensando articulações possíveis. Psicologia Eु Sociedade, 19 (número especial), 29-37.

Dal Magro, M. L. P. D. (2006). Os sentidos do trabalho para sujeitos inseridos em "empreendimentos solidários". Dissertação de Mestrado, Programa de Pós-Graduação em Psicologia, Universidade Federal de Santa Catarina, Florianópolis.

Demazière, D. \& Dubar, D. (2006). Trajetórias profissionais e formas identitárias: uma teorização. In N. A. Guimarães \& H. Hirata (Orgs.), Desemprego: trajetórias, identidade, mobilizações (pp. 165-187). São Paulo: SENAC.

Dubar, C. (2006). Trajetórias sociais e formas identitárias: alguns esclarecimentos conceituais e metodológicos. Educação Ë Sociedade, 19 (62), 13-30.

Franco, M. L. P. B. (1994). Que é análise de conteúdo. In M. L. P. B. Franco (Org.), Ensino médio: desafios e reflexões (pp.159-185). Campinas: Papirus.

Gaulejac, V. de. (2000). La vie, le roman, 1’histoire. Revie International de Psychosociologie, 6 (14), 110-116.

Gaulejac, V. de. (2005). O âmago da discussão: da sociologia do indivíduo à sociologia do sujeito. Cronos, Natal-RN, $5 / 6(1 / 2), 59-77$.

Gorz, A. (1982). Adeus ao proletariado. Rio de Janeiro: Forense.

Guimarães, N. A. \& Hirata, H. (2006). Apresentação. In N. A. Guimarães \& H. Hirata (Orgs.), Desemprego: trajetórias, identidade, mobilizações (pp. 9-21). São Paulo: SENAC.

Hall, S. (2004). Quem precisa da identidade? In T. T. Da Silva (Org.), Identidade e diferença: a perspectiva dos Estudos Culturais (pp. 103-133). Petrópolis: Vozes.

Harvey, D. (2000). Condição pós-moderna: uma pesquisa sobre as origens da mudança cultural. São Paulo: Loyola.

Heloani, R. \& Capitão, C. G. (2007). Formulações gerais sobre o objeto de pesquisa em Psicologia: estudo de caso. In M. C. M. Matias \& J. A. D. Abib (Orgs.), Sociedade em transformação: estudo das relações entre trabalho, saúde e subjetividade (pp. 17-35). Londrina: EDUEL. 
Jesus, J. W. P. de (1998). A reforma do aparelho de Estado. In Anais do XXII Encontro Anual da ANPAD. Foz do Iguaçu: Associação Nacional de Pesquisa e Pós-Graduação em Administração.

Kovács, I. (2005). Emprego flexível em Portugal: alguns resultados de um projecto de investigação. In I. Kovács (Org.), Flexibilidade no emprego: riscos e oportunidades (pp. 11-53). Oeiras, Portugal: Celta.

Laplanche, J. E. \& Pontalis, J. B. (1971). Vocabulário de Psicanálise. São Paulo: Martins Fontes.

Martin-Baró, I. (1985). Acción e ideología: psicología social desde Centroamérica. San Salvador: UCA Editores.

Marx, K. (1968). Processo de trabalho e processo de produzir mais-valia. In O Capital (livro 1, vol. 1, cap. V). Rio de Janeiro: Civilização Brasileira.

Marx, K. (1983). Trabalho alienado (Primeiro manuscrito) In E. Fromm (Org.), O conceito marxista de homem. Rio de Janeiro: Zahar.

Offe, C. (1989). Trabalho como categoria sociológica fundamental? In Trabalho E Sociedade: problemas estruturais e perspectivas para o futuro da sociedade do trabalho (pp. 13-41). Rio de Janeiro: Tempo Brasileiro.

Pateman, C. (1992). Participação e teoria democrática. Rio de Janeiro: Paz e Terra.

Pochmann, M. (2006). Desempregados do Brasil. In R. Antunes (Org.), Riqueza e miséria do trabalho no Brasil (pp. 59-73). São Paulo: Boitempo.

Rey, F. L G. (2002). Pesquisa qualitativa em psicologia: caminhos e desafios. São Paulo: Pioneira Thomson.

Santos, B. de S. (2001). Pela mão de Alice: o social e o político na pós-modernidade. São Paulo: Cortez.

Sawaia, B. B. (1999a). Introdução: exclusão ou inclusão perversa? In B. B. Sawaia (Org.), As artimanhas da exclusão: análise psicossocial e ética da desigualdade social (pp. 7-13). Petrópolis: Vozes.

Sawaia, B. B. (1999b). O sofrimento ético-político como categoria de análise da dialética exclusão/inclusão. In B. B. Sawaia (Org.), As artimanhas da exclusão: análise psicossocial e ética da desigualdade social (pp. 7-13). Petrópolis: Vozes.

Singer, P. (2000). Globalização e desemprego: diagnóstico e alternativas. São Paulo: Contexto.

Stecher, A., Godoy, L. \& Díaz, X. (2005). Relaciones de producción y relaciones de genero en un mundo en transformación. In L. Schvarstein \& L. Leopold (Orgs.), Trabajo y subjetividad: entre lo existente y lo necesario (pp. 71-11). Buenos Aires: Paidós.

Tolfo, S. da R., Coutinho, M. C., Almeida, A. R., Baasch, D. \& Cugnier, J. S. (2005). Revisitando abordagens sobre sentidos e significados do trabalho. In Anais do Fórum CRITEOS. Porto Alegre: UFRGS.

Tolfo S. da R. \& Piccinini, V. (2007). Sentidos e significados do trabalho: explorando conceitos, variáveis e estudos empíricos brasileiros. Psicologia Eु Sociedade, 19 (número especial), 38-46.

Triviños, A. N. S. (1987). Introdução à pesquisa em ciências sociais: a pesquisa qualitativa em educação. São Paulo: Ática.

\section{Endereço para correspondência \\ chalfin@mbox1.ufsc.br}

Recebido em: 02/09/2008

Revisado em: 02/12/2008

Aprovado em: 10/12/2008 